AperTO - Archivio Istituzionale Open Access dell'Università di Torino

Effects of attentional and cognitive variables on unilateral spatial neglect

This is a pre print version of the following article:

Original Citation:

Availability:

This version is available http://hdl.handle.net/2318/1566569

since 2022-11-25T13:51:13Z

Published version:

DOI:10.1016/j.neuropsychologia.2016.05.004

Terms of use:

Open Access

Anyone can freely access the full text of works made available as "Open Access". Works made available under a Creative Commons license can be used according to the terms and conditions of said license. Use of all other works requires consent of the right holder (author or publisher) if not exempted from copyright protection by the applicable law. 


\title{
Effects of attentional and cognitive variables on unilateral spatial neglect
}

\author{
Raffaella Ricci, ${ }^{\mathrm{a}, \mathrm{b}, *}$ Adriana Salatino, ${ }^{\mathrm{a}}$ Francesca Garbarini, ${ }^{\mathrm{a}}$ Irene Ronga, ${ }^{\mathrm{a}}$ Rosanna Genero, ${ }^{\mathrm{c}}$ Anna Berti, ${ }^{\mathrm{a}, \mathrm{b}}$ \\ Marco Neppi-Mòdona ${ }^{a, b}$ \\ ${ }^{a}$ Department of Psychology, SAMBA (SpAtial, Motor and Bodily Awareness) Research Group, University of Turin, Turin, Italy \\ ${ }^{\mathrm{b}}$ Neuroscience Institute of Turin (NIT), University of Turin, Italy \\ c Casa di Cura Papa Giovanni XXIII, Pianezza, Italy
}

\section{A R T I C L E I N F O}

Article history:

Received 25 December 2015

Received in revised form 27 April 2016

Accepted 3 May 2016

Available online $\mathrm{xxx}$

Keywords:

Spatial attention

Neglect

Visual search

Cognitive load

Sustained attention

\section{A B S T R A C T}

Patients with visuospatial neglect when asked to cancel targets partially or totally omit to cancel contralesional stimuli. It has been shown that increasing the attentional demands of the cancellation task aggravates neglect contralesionally. However, some preliminary evidence also suggests that neglect might be worsened by engaging the patient in a demanding, non-spatial, cognitive activity (i.e. a mathematical task). We studied cancellation performance of 16 patients with right-hemisphere lesions, 8 with neglect, 8 without neglect, and 8 age-matched healthy control participants by means of five cancellation tasks which varied for the degree of attentional and/or high level cognitive demands (preattentive and attentive search of a visual target, searching for numbers containing the digit 3, even numbers, and multiples of 3 ).

Results showed that attentive search of visual targets, relative to the preattentive search condition, aggravated neglect patients' performance. Moreover, searching for multiples not only worsened spatial neglect contralesionally, but also slowed down performance of patients with right-hemisphere lesions without neglect.

Our findings further demonstrate the presence of specific deficits of attention in neglect. In addition, the worse performance of patients without neglect in the 'multiples of 3' task is consistent with the evidence that right-hemisphere lesions per se impair the ability to maintain attention (i.e. sustained attention). This suggests that the exacerbation of neglect during execution of a demanding, non-spatial, cognitive task might be explained by a deficit of sustained attention in addition to a selective deficit of spatial attention.

(C) 2016 Published by Elsevier Ltd.

\section{Introduction}

Patients with visuospatial neglect following unilateral brain lesions to the right hemisphere fail to orient towards, attend to or act upon stimuli located in contralesional space (Heilman et al., 1993). Typically, when neglect patients are asked to search for and cancel targets printed on a sheet of paper (cancellation tasks, e. g. Albert, 1973; Diller et al., 1974; Mesulam, 1985; Wilson et al., 1987), they do not explore contralateral space effectively and omit to detect stimuli located in that side of space, even if they are free to move their head and eyes. This disturbance has been interpreted as a consequence of the disruption of selective spatial attentional processes (Kinsbourne, 1987; Heilman, et al., 1993). Moreover, since extensive right-hemisphere lesions also impair the ability to maintain sustained attention (Wilkins et al., 1987; Pardo et al., 1991; Robertson et al., 1997, 1998), some authors have suggested a possible interaction between the damage to the spatial attentional system implicated in neglect and a co-occurence deficit of the sustained attention system (Heilman et al., 1978; Robertson et al., 1998; Posner, 1993; Robertson et al., 1995, 1997). While the spatial selectivity component of human attention enhances perception of stimuli located in specific regions of space, the alertness component of attention allows the execution of effortful vigilance tasks (i.e. focusing attention to subtle

\footnotetext{
* Corresponding author at: Department of Psychology, SAMBA (SpAtial, Motor and Bodily Awareness) Research Group, University of Turin, Turin, Italy.

Email address: raffaella.ricci@unito.it (R. Ricci)
}

sensory stimuli, filtering irrelevant information and maintaining alertness for the duration of the task) independently of stimulus location (Pardo et al., 1991).

Patients with neglect may manifest different degrees of spatial impairment, suggesting that the disorder is not an all-or-none phenomenon. In addition, it may dissociate across frames of reference (e. g. egocentric and allocentric coordinates, Rusconi et al., 2005), sectors of space (e. g. personal, peripersonal and extrapersonal space, Bisiach et al., 1986; Berti and Frassinetti, 2000; Neppi-Mòdona et al., 2007), and, within the same spatial domain, it may vary according to task demands. Nonetheless, the specific determinants of neglect within the same spatial domain are not yet fully understood. For instance, in cancellation tasks, other variables besides spatial location (Chatterjee et al., 1999) may affect neglect severity.

Attentional theories of neglect (Kinsbourne, 1987; Heilman, et al., 1993 ) predict that increasing the attentional demands of the cancellation task, would aggravate patients' performance. Indeed, it has been shown that target saliency (Weintraub and Mesulam, 1988; Kaplan et al., 1991; Aglioti et al., 1997; Husain and Kennard, 1997; Chatterjee et al., 1999), stimuli number and density (Mark et al., 1988; Eglin et al., 1989; Chatterjee et al., 1992; Kartsounis and Findley, 1994; Mennemeier et al., 1998; Chatterjee et al., 1999; Neppi-Mòdona et al., 2002; Ricci et al., 2004; Pia et al., 2013), targets and distractors ratio (Kaplan et al., 1991), distractors similarity (Riddoch and Humphreys, 1987), and stimuli perceptual configuration defined by gestalt grouping principles (Pia et al., 2004) may modulate neglect. These modulations are mainly related to bottom-up stimulus process- 
ing stages. A number of studies have also shown that top-down attentional requests can influence neglect patients' performance. For instance, top-down task-demands (Sarri et al., 2009) and dual task attentional paradigms (Robertson and Frasca, 1992) affect neglect severity, even if stimulus perceptual features are kept constant. Finally, different kind of backgrounds that trigger either preattentive/parallel (immediate, effortless) or attentive/serial (slow, effortful) search (Treisman and Gelade, 1980; Bergen and Julesz, 1983), can influence target search performance (Aglioti et al., 1997).

Interestingly, other variables, not explicitly linked to the attentional domain, seem to affect neglect (Ishiai et al., 1990; Chatterjee et al., 1992; Tegnér and Levander, 1991; Marshall and Halligan, 1996; Mark and Heilman, 1997). In particular, preliminary findings from a single case study suggested that the cognitive demands required to identify specific targets modulate neglect severity. Mennemeier et al. (2004) described a patient with a right-hemisphere lesion and left neglect whose cancellation bias worsened when target selection required to perform a mathematical task. Specifically, in the critical condition the patient was asked to search for the multiples of a specific number. This cognitive task is likely to require a greater amount of attentional resources to be accomplished. Because sustained attention might be impaired in right hemisphere patients (Wilkins et al., 1987; Pardo et al., 1991; Robertson et al., 1997; 1998), it is possible that worsening of neglect in Patient of Mennemeier et al. (2004) was due to a concomitant deficit of both selective spatial attention and sustained attention. Since sustained attention can be considered a basic attentional function that determines the efficacy of higher attentional processes (e. g. selective spatial attention) and, in general, of cognitive abilities (Sarter et al., 2001), an influence of sustained attention on spatial attention during a demanding task might be expected. However, to our knowledge, this is the only existing evidence suggesting that a, non-spatial, demanding cognitive process, activated in order to accomplish the task, worsens neglect during stimuli cancellation. No other study has validated or further explored this issue at a group level in patients with and without neglect and in healthy controls. The only evidence that task-related attentional load can worsen neglect and/or extinction on cancellation (Robertson and Frasca, 1992) or detection tasks (Robertson and Frasca, 1992; Bonato et al., 2010, 2013, 2015) comes from dual task paradigms. However, carrying-out simultaneously a cognitive and a cancellation or detection task requires to divide attention between concurrent activities rather than increasing the 'cognitive' load of the current visuo-spatial task.

Here we investigated the influence of different categories of perceptual and cognitive load on cancellation performance in patients with right-hemisphere lesion with and without neglect, and in agematched healthy participants. In two experimental conditions we manipulated bottom-up stimuli perceptual features (experiment 1), and in three conditions we manipulated top-down task demands (experiment 2).

In experiment 1 , the three groups performed two cancellation tasks that required either 'preattentive' or 'attentive' texture segmentation (Aglioti et al., 1997) in order to segregate targets from distractors (Julesz, 1981, 1987; Bergen and Julesz, 1983; Sagi and Julesz, 1985). On the basis of previous findings (Aglioti et al., 1997) and according to attentional theories of neglect (Heilman et al., 1987; Kinsbourne, 1987), we expected to observe an attentional-dependent modulation of cancellation performance in neglect patients and not in the other groups (i.e. a worse performance on the attentive than on the preattentive texture condition).

In experiment 2, participants were asked to identify target stimuli (i.e. numbers) according to different task demands. As in the study of
Mennemeier et al. (2004), in the control condition participants searched for stimuli containing a specific number, whereas in the critical high-load cognitive condition participants were asked to search for multiples of the same number. In addition, in a low-load cognitive condition, subjects were asked to search for even numbers. We assumed that this latter task implied, on the one hand, a higher cognitive load than searching for a specific number, but on the other hand, a lower cognitive load than searching for multiples. We hypothesized that if unilateral visual neglect is exclusively accounted for by a deficit of visuospatial attention, then we should not observe any effect on the visuospatial bias by the cognitive load, given that targets and distractors perceptual features (numbers) were kept constant. On the other hand, if unilateral visual neglect is also due to a non-spatial deficit in maintaining sustained attention (Robertson et al., 1995, 1997, 1998), then increasing the cognitive load should further aggravate the spatial orientation bias. Indeed, sustained attention is an important component of 'top-down' processes that mediate knowledge-driven target detection and selection.

Searching for the number 3 was expected to lead to a performance similar to the 'attentive' task of experiment 1 , since both tasks involved serial attentive search of well-defined visual features. Searching for even numbers was supposed to be cognitively less demanding than searching for multiples, and therefore a possibility was that this condition produced a better performance than searching for multiples. In addition, searching for even numbers was hypothesized to be cognitively more demanding than searching for the number 3 (because it requires access to a stored semantic representation of number knowledge, Dehaene et al., 1993) and therefore was expected to produce worse performance than searching for $3 \mathrm{~s}$ In order to be functionally related to a deficit of the selective spatial attention system, any decrement in performance should be limited to the group of neglect patients. On the other hand, a concomitant decrement in performance in patients without neglect would suggest a modulatory influence of the sustained attention system over the spatial attentional system.

The method proposed here is complementary to dual-task computer-based detection paradigms that are able to unveil disorders of contralesional space awareness in patients with right hemisphere lesions not showing neglect at paper-and-pencil cancellation tasks (Bonato et al., 2010, 2013, 2015). Indeed, it allows studying patients with spatial neglect at standard tests, even if they are affected by visual field defects.

\section{Materials and method}

\subsection{Participants}

Eight right brain-damaged patients with neglect $(\mathrm{N}+)$, eight without neglect $(\mathrm{N}-)$ and eight age-matched healthy volunteers participated in the study. Participants were all right-handers, with the exception of one $\mathrm{N}-$ patient (\#5) that was a left-hander converted into righthander. Participants' demographic and clinical data are reported in Table 1. Patients did not show any sign of mental impairment as evaluated by the MMSE (Folstein et al., 1975). Patients' contralesional neglect was assessed using the letter $\mathrm{H}$ cancellation task (Diller and Weinberg, 1977) and the bisection of five 180-mm long and 1-mm thick black horizontal lines (Bisiach et al., 1999). Patients' contralesional neglect was defined on the basis of either (or both) of the following criteria: (1) mean bisection error towards the ipsilesional side exceeding $10 \mathrm{~mm}$; (2) left-side minus right-side omissions on the cancellation task (Diller and Weinberg, 1977) being equal to 5 or more (in Table 1 are reported individual scores of patients on bisection and cancellation). Visual field defects (VFD) were evaluated us- 
Table 1

Demographic and clinical data of patients with neglect $(\mathrm{N}+)$, without neglect $\left(\mathrm{N}^{-}\right)$and demographic data of healthy participants.

\begin{tabular}{|c|c|c|c|c|c|c|c|c|c|c|}
\hline \multicolumn{11}{|l|}{$\mathrm{N}+$ patients } \\
\hline & Sex & Age & $\begin{array}{l}\text { Education } \\
\text { (years) }\end{array}$ & $\begin{array}{l}\text { Lesion (CT/MRI } \\
\text { scan) }\end{array}$ & Etiology & $\begin{array}{l}\text { Length of illness } \\
\text { (days) }\end{array}$ & MMSE & $\begin{array}{l}\text { Bisection mean error } \\
\text { (SD) }\end{array}$ & DILLER (omissions L-R) & VFD \\
\hline 1 & $\mathrm{~F}$ & 77 & 5 & $\mathrm{PT}$ & I & 26 & 28 & $+4.2(4.49)$ & $6-1$ & $0-0$ \\
\hline 2 & M & 75 & 13 & cr O th & I & 48 & 27 & $+13.5(7.78)$ & $11-4$ & $3-1$ \\
\hline 3 & M & 64 & 12 & F O P T bg ci cs & I & 106 & 24 & $+42.8(3.49)$ & $32-1$ & $3-3$ \\
\hline 4 & M & 63 & 5 & O P T & $\mathrm{H}$ & 54 & 28 & $+18.9(5.67)$ & $8-3$ & $1-1$ \\
\hline 5 & M & 62 & 10 & $\mathrm{O}$ peris & I & 48 & 28 & $+3.6(18.4)$ & $51-31$ & $3-2$ \\
\hline 6 & M & 70 & 5 & bg F O T & I & 64 & 29 & $+12.2(4.15)$ & $46-2$ & $1-1$ \\
\hline 7 & $\mathrm{~F}$ & 72 & 13 & ci & I & 70 & 27 & $+5.4(4.98)$ & $51-28$ & $1-1$ \\
\hline 8 & $\mathrm{~F}$ & 61 & 5 & $\mathrm{P} \mathrm{T}$ & I & 53 & 25 & $+8.3(16.04)$ & $24-19$ & $1-1$ \\
\hline \multicolumn{11}{|l|}{$\mathrm{N}-$ patients } \\
\hline & Sex & Age & $\begin{array}{l}\text { Education } \\
\text { (years) }\end{array}$ & $\begin{array}{l}\text { Lesion (CT/MRI } \\
\text { scan) }\end{array}$ & Etiology & $\begin{array}{l}\text { Length of illness } \\
\text { (days) }\end{array}$ & MMSE & $\begin{array}{l}\text { Bisection } \mathrm{r} \\
\text { (SD) }\end{array}$ & $\begin{array}{c}\text { mean error DILLER (omissions } \\
\text { L-R) }\end{array}$ & VFD \\
\hline 1 & M & 75 & 7 & cr pons & I & 31 & 27 & $-2.4(3.65)$ & $0-0$ & $0-0$ \\
\hline 2 & M & 61 & 18 & hyp & I & 68 & 28 & $-0.7(3.52)$ & $0-0$ & $0-0$ \\
\hline 3 & M & 71 & 10 & $\mathrm{ci}$ & $\mathrm{H}$ & 41 & 29 & $-1.0(0.63)$ & $0-0$ & $0-0$ \\
\hline 4 & $\mathrm{~F}$ & 59 & 11 & $\mathrm{P}$ & $\mathrm{H}$ & 169 & 28 & $-0.8(1.60)$ & $1-3$ & $0-0$ \\
\hline 5 & $\mathrm{~F}$ & 79 & 8 & ci & I & 36 & 30 & $+5.0(0.89)$ & $1-0$ & $0-0$ \\
\hline 6 & $\mathrm{~F}$ & 77 & 8 & $\mathrm{~F} \mathrm{~T}$ & $\mathrm{H}$ & 63 & 28 & $+5.5(2.80)$ & $5-2$ & $0-0$ \\
\hline 7 & $\mathrm{~F}$ & 73 & 6 & $\mathrm{ci}$ & I & 35 & 27 & $+2.0(3.23)$ & $2-1$ & $0-0$ \\
\hline 8 & $\mathrm{~F}$ & 74 & 8 & ci cr & I & 38 & 30 & $-0.3(0.30)$ & $0-0$ & $0-0$ \\
\hline \multicolumn{11}{|l|}{$\begin{array}{l}\text { Healthy } \\
\text { controls }\end{array}$} \\
\hline & & & & Sex & Age & Education (years) & & & & \\
\hline 1 & & M & & 65 & & 5 & & & & \\
\hline 2 & & $\mathrm{~F}$ & & 66 & & 5 & & & & \\
\hline 3 & & $\mathrm{M}$ & & 64 & & 5 & & & & \\
\hline 4 & & $\mathrm{~F}$ & & 70 & & 5 & & & & \\
\hline 5 & & $\mathrm{M}$ & & 57 & & 12 & & & & \\
\hline 6 & & $\mathrm{~F}$ & & 68 & & 5 & & & & \\
\hline 7 & & $\mathrm{~F}$ & & 65 & & 8 & & & & \\
\hline 8 & & $\mathrm{M}$ & & 65 & & 8 & & & & \\
\hline
\end{tabular}

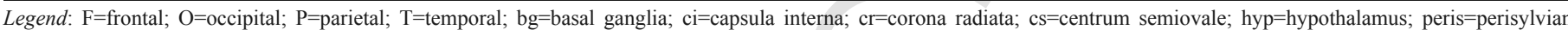

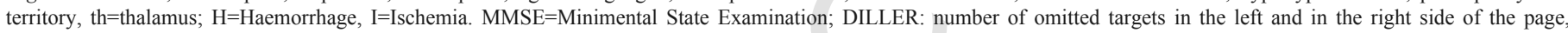

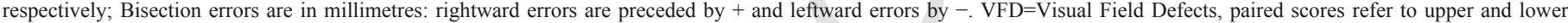
contralesional visual field quadrant; they range from 0 , no impairment, to 3 , maximum impairment.

ing a confrontation test in which patients were asked to detect unilateral movements of the examiner's finger in the left/right upper and lower visual quadrants (Bisiach et al., 1986, 1997). Ten single and 10 double, symmetrical and simultaneous visual stimuli were given, by the examiner. Stimuli were administered following a fixed random order and scores for the upper and then lower quadrant were recorded. The scores were assigned as follow: $0=$ eight or more double stimuli and all single stimuli were perceived; $1=$ less than eight double, but more than seven single stimuli were perceived; $2=$ Four to seven single stimuli were perceived; $3=$ less than four single stimuli were perceived. A score of 3 for the upper or lower quadrant indicated the presence of quadrantanopia, while a score of 3 for both quadrants indicated hemianopia. A score of 1 was an index of visual extinction (see Table 1). On this test, $37.5 \%$ (3/8) of $\mathrm{N}+$ patients showed severe VFD, $50 \%(4 / 8)$ of them had mild VFD and $12.5 \%(1 / 8)$ had no VFD. On the other hand, none of $\mathrm{N}-$ patients manifested signs of visual field defects. Data on lesion location came from CT or MRI scans. Neuroradiological data in the different groups of patients indicated temporal lobe damage in about $63 \%$ of $\mathrm{N}+$ and in about $13 \%$ of $\mathrm{N}-$; parietal lobe damage in $50 \%$ of $\mathrm{N}+$ and in about $13 \%$ of $\mathrm{N}-$; frontal lobe damage in $25 \%$ of $\mathrm{N}+$ and in about $13 \%$ of $\mathrm{N}-$; and occipital lobes damage in $63 \%$ of $\mathrm{N}+$ and in $0 \%$ of $\mathrm{N}-$. Finally, subcortical lesions were present in $50 \%$ of $\mathrm{N}+$ and in $75 \%$ of $\mathrm{N}-$ (Table 1). In one $\mathrm{N}+$ patient (\# 5) the lesion was reported as involving the perisylvian territory (besides the occipital lobe).

Normal subjects $(\mathrm{C})$ and patients without neglect $(\mathrm{N}-)$ did not differ from neglect patients $(\mathrm{N}+)$ for age $[\mathrm{C}: t$-test $(7)=1.30 \mathrm{p}=0.233$; $\mathrm{N}-: t$-test $(7)=0.88 \mathrm{p}=0.404]$ or educational level [C: $t$-test $(7)=1.27$ $\mathrm{p}=0.246 ; \mathrm{N}-:$-test $(7)=0.65 \mathrm{p}=0.536]$. All participants gave informed consent to participate in accord with local ethics.

\subsection{Stimuli and procedure}

Participants were asked to perform a series of cancellation tasks. In particular, in experiment 1 , they had to detect targets dispersed among distractors on the following two conditions: (1) preattentive and (2) attentive search of a visual shape (see Aglioti et al., 1997). In experiment 2, they had to search for (1) digits containing the number 3 (N3), (2) even numbers (EN), or (3) multiples of the number 3 (M3) (see Mennemeier at al., 2004). All patients performed experiment 1 first.

\subsection{Experiment 1}

Participants were asked to perform two modified versions of the cancellation tasks employed by Aglioti et al. (1997). Specifically, they had to cross out with a pencil (using their ipsilesional hand) targets presented among distractors in the following two conditions: preattentive and attentive search of a visual element (see Aglioti et al., 1997). Visual displays for the 'preattentive' and the 'attentive' conditions had different textures (Fig. 1). The two textures were built so that they differed in the number and position of distinct local features. According to Julesz' view (Julesz, 1981, 1987) and to existing evidence (Aglioti et al., 1997), the preattentive display would have determined a quick and effortless visual search, while the attentive display a slow and effortful search. In the preattentive texture, the tar- 

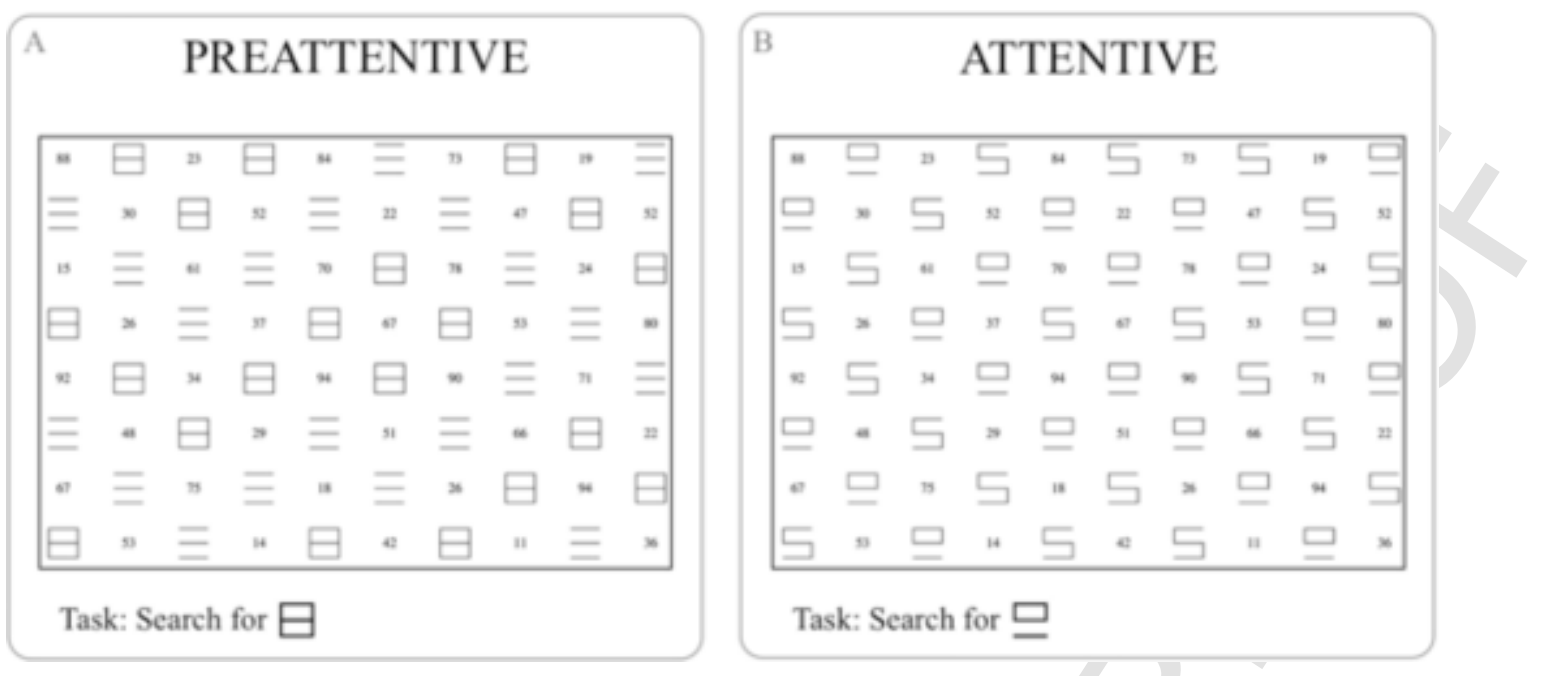

Fig. 1. Examples of the preattentive (A) and attentive (B) tasks employed in experiment 1.

get element differed from the distractor element by the presence of two additional vertical segments flanking the three horizontal segments composing the distractor element (Fig. 1A). In the attentive texture, each target element differed from a distractor element because one of the composing line segments was differently positioned (Fig. 1B). For each texture, 80 items were arranged in a matrix of 8 rows by 10 columns on an A4 sheet of white paper. Forty of the 80 items were shapes and the other 40 were numbers. In each column there were 4 shapes and 4 numbers. The 2 target elements presented in each column were spatially organized according to a pseudo-random order. For each texture there were a total of 20 target elements, pseudo-randomly distributed so that 4 of them were presented in each quadrant. Distractor elements consisted in 20 shapes. However also the 40 numbers presented on the display had to be ignored. For each condition, the display was always the same.

Each cancellation task was preceded by a pretest in which participants were asked to discriminate the target from the distractor. Subjects who failed in this discrimination task were not included in the study. The preattentive and attentive tasks were presented twice according to an ABBA order for half of the participants and a BAAB order for the other half, for each group. The cancellation display was positioned at a reading distance and was aligned with the participant's body vertical midline. Participants were tested in a quiet and welllit room; exploratory eye and head movements were allowed. Participants were informed that the time spent to complete each cancellation task was recorded, but that accuracy was more important than execution time.

\subsubsection{Statistical analysis}

Omissions (O), Execution Time (ET) and False Alarm (FA) were recorded.

Omission errors were divided into two groups: left or right according to whether the error was on the left or on the right side of the page, respectively. A false alarm (FA) was recorded whenever a distractor was crossed out as a target. False alarms were divided into two groups: left and right according to whether the error was in the left or in the right side of the page. The execution time (ET), the time between the first and the last cancellation (Donnelly et al., 1999), was manually recorded with a stopwatch starting from the 'go' signal given by the experimenter at the beginning of each task, to the instant in which the participant stopped exploring the visual display.
Errors and ETs were analyzed by means of separate analysis of variance (ANOVAs) for mixed design models. Post-hoc analyses were performed using the Newman Keuls test. The percentage of FA was very low for $\mathrm{N}+(=0.09 \%)$ and no FA were produced by $\mathrm{N}-$ and $\mathrm{C}$. Therefore no further analysis was performed on this variable.

For the group of neglect patients, a correlation analysis was performed between measures of neglect on the neuropsychological tasks (line bisection and Diller cancellation tasks) and omissions or execution times on the experimental tasks. For the clinical (Diller) and experimental cancellation tasks, correlation analysis was performed on the difference between left and right-sided omissions.

\subsection{Experiment 2}

In this experiment the same participants of experiment 1 were asked to search for: (1) digits containing the number 3 (N3) (Mennemeier at al., 2004), (2) even numbers (EN), (3) multiples of 3 (M3) (Mennemeier at al., 2004). Each of the three tasks was performed on preattentive and attentive backgrounds (see Fig. 2). Participants were instructed to cross out with a pencil (using their ipsilesional arm) all targets in the 6 visual configurations (N3, EN, M3 performed on attentive and preattentive backgrounds). In each cancellation condition, there were 20 target numbers and 20 numbers that were distractors. For each experimental condition the numbers used as target stimuli were all different. Similarly, distractors were all different numbers. This served to make sure that participants were effectively accomplishing the requested tasks. The 40 elements constituting the visual background had to be ignored.

In task N3, participants were requested to detect all numbers containing the digit 3 , for example 32 or 83 (Fig. 2A). In this task targets were one- or two-digit numbers (from 1 to 99) containing the digit 3 . Two targets were presented in each column: one target had the 3 as first digit (i.e. the left digit) and the other target had the 3 as second digit (i.e. the right digit).

In the EN task (i.e. searching for even numbers) participants were required to cross out all even numbers present in the display (Fig. 2B). There were five targets in each quadrant distributed according to a pseudo-random order, so that within each quadrant targets ended with one of the five possible even digits (i.e. $0,2,4,6$ and 8). In each column there were two targets and two distractors.

In the M3 task, participants had to search for multiples of 3 (Fig. $2 \mathrm{C})$. Ten out of 20 targets belonged to the number board, while the 


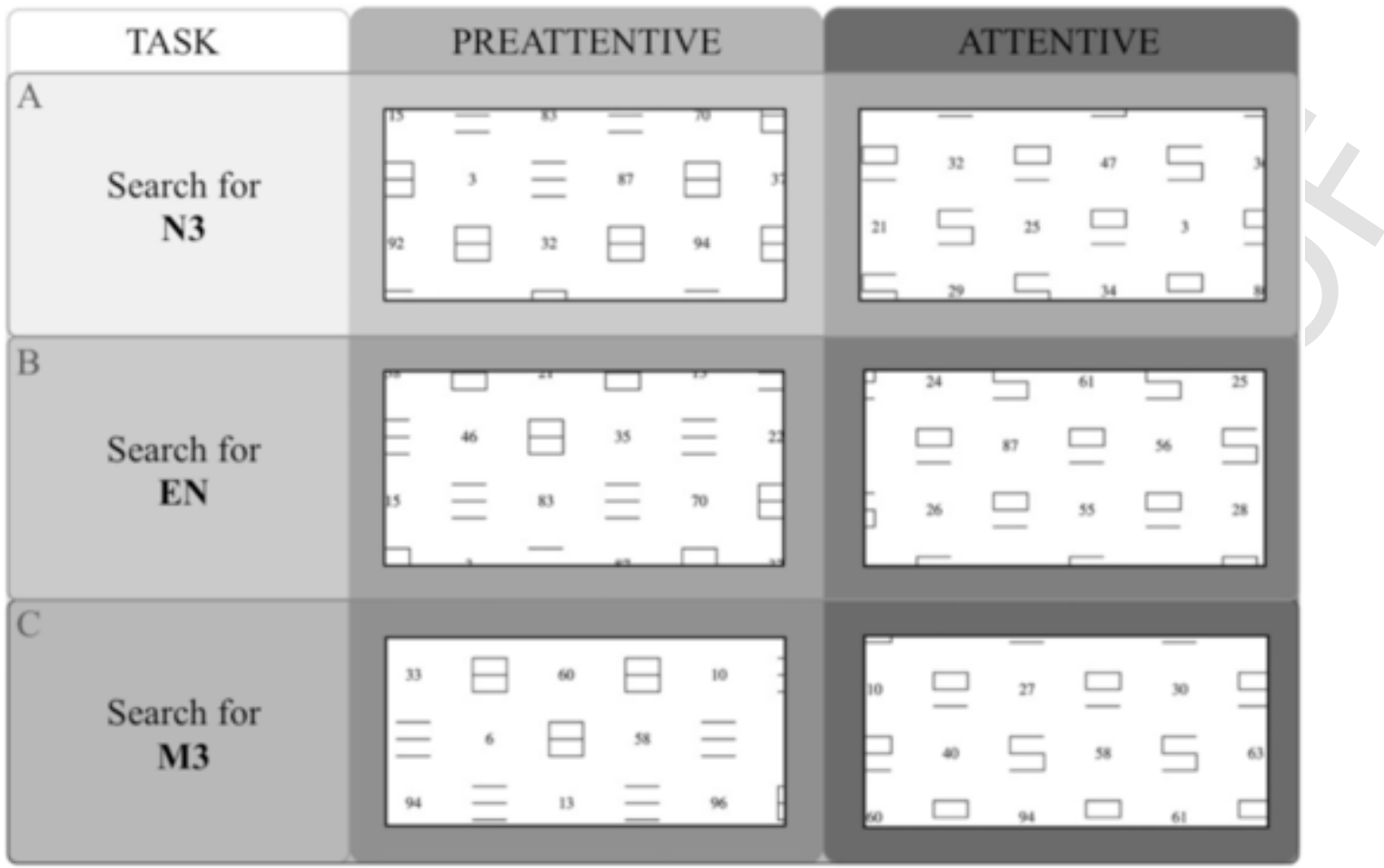

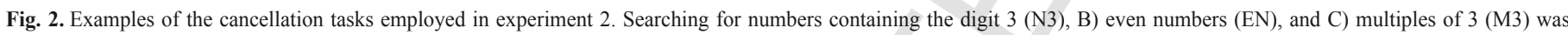
performed on preattentive and attentive backgrounds. In the figure the visual stimuli size is magnified to allow to appreciate the stimuli details.

other 10 were multiples of 3 , ranging from 33 to 99 . In each row there were two targets: one belonging to the first group (number board of 3 ) while the other was a multiple higher than 30 .

For each condition, the display was always the same.

All the cancellation tasks were verbally illustrated. The participants' mathematic abilities were screened before administering the experimental tasks by asking them to report some examples of even numbers and of multiples of 3 . Hence, they were asked to identify on three different displays, examples of digits containing the number 3 , of even numbers and of multiple of 3 (each display contained stimuli which were different from those used in the experimental tasks). Participants incapable to accomplished these tasks during screening were not included in the study. The six cancellation tasks were presented twice. First, they were administered following a pseudo-random sequence with two constraints: two consecutive cancellations could not have the same background or task instructions. Then, the pseudo-random sequence of cancellation tasks was repeated, but according to an inverse order.

The cancellation display was positioned at a reading distance and was aligned with the participant's body vertical midline. Subjects were tested in a quiet and well-lit room; exploratory eye and head movements were allowed. Participants were informed that the time spent to complete each cancellation task was recorded, but that accuracy was more important.

\subsubsection{Statistical analysis}

As for experiment 1, omissions (O), false alarms (FA), and Execution times (ET) were recorded (see experiment 1 for details). Errors and ETs were analyzed by means of separate analysis of variance (ANOVAs) for mixed design models. The percentage of FA was very low $(\mathrm{N}+=0.22 \% ; \mathrm{N}-=0.13 \% ; \mathrm{C}=0.08 \%)$ and therefore no further analysis was performed. For the group of neglect patients, a correlation analysis was performed between measures of neglect on the clin- ical neuropsychological tasks (line bisection and Diller cancellation tasks) and omissions or execution times on the experimental tasks. For the clinical (Diller) and experimental cancellation tasks, correlation analysis was performed on the difference between left and right-sided omissions.

\section{Results \\ 3.1. Experiment 1}

On the omission data a $3 \times 2 \times 2$ Anova with one between-subject factor, Group (three levels: $\mathrm{N}+, \mathrm{N}-, \mathrm{C}$ ), and two within-subject factors, Side (two levels: left, right) and Task (two levels: preattentive, attentive) was performed.

The factor Group was significant $[\mathrm{F}(2,21)=10.71 ; \mathrm{p}=.0006$; partial $\left.\eta^{2}=0.504\right]$. Post-hoc analyses showed that $\mathrm{N}+$ omitted more targets $(\mathrm{N}+$ mean $=1.21, \mathrm{SD}=1.73)$ than the other two groups $(\mathrm{N}-$ mean $=0.12$, $\mathrm{SD}=0.28 ; \mathrm{C}$ mean $=0.01, \mathrm{SD}=0.08 ; \mathrm{p}<.001$ for each comparisons $)$. The factor Task $\left[\mathrm{F}(2,21)=6.8 ; \mathrm{p}=.005\right.$; partial $\left.\eta^{2}=0.261\right]$ and the factor Side $\left[F(2,21)=12.26 ; p=.002\right.$; partial $\left.\eta^{2}=0.368\right]$ were also significant. Post-hoc analyses indicated that more omissions were made on the attentive (mean=0.62, $\mathrm{SD}=1.31$ ) than on the preattentive task (mean $=0.28, \mathrm{SD}=0.92)$ and on the left $($ mean $=0.73, \mathrm{SD}=1.51)$ than on the right (mean $=0.16, \mathrm{SD}=0.41$ ) side of the page.

A significant Group X Side interaction $[F(2,21)=14.35 ; p=.0001$; partial $\left.\eta^{2}=0.577\right]$ was also present and was accounted for by a higher number of omissions in $\mathrm{N}+$ patients' left side with respect to their right side $(\mathrm{p}<.0005$ for each comparisons; see Fig. 3A). Note that in both $\mathrm{N}-$ and $\mathrm{C}$ groups no significant side effect was found. Finally a significant Group X Task interaction $[\mathrm{F}(2,21)=6.8 ; \mathrm{p}=.005$; partial $\left.\eta^{2}=0.393\right]$ was accounted for by the fact that only $\mathrm{N}+$ patients made 


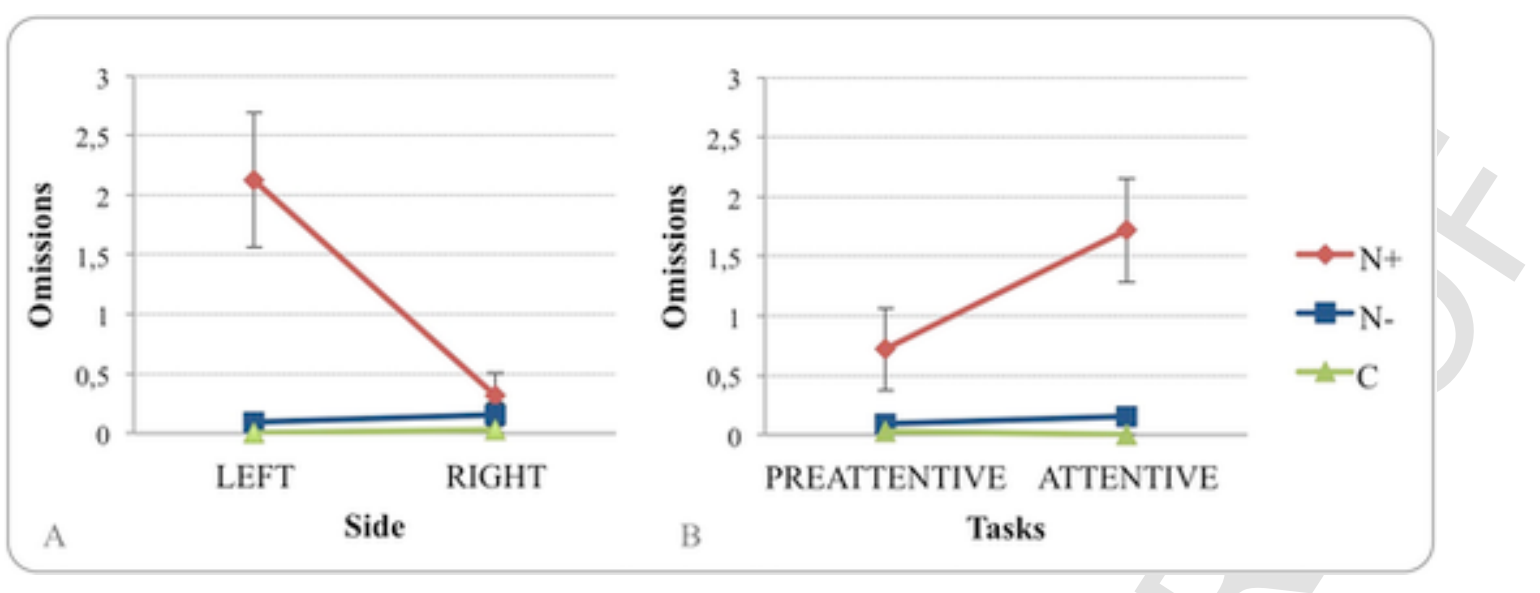

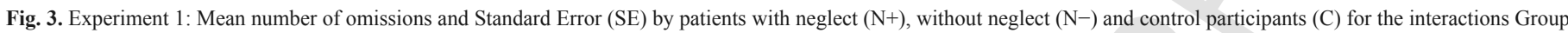

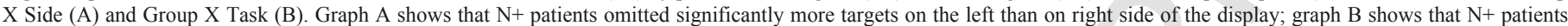
omitted significantly more targets in the attentive than in the preattentive task. No significant differences were found for the other two groups.

significantly more omissions on the attentive than on the preattentive texture ( $p=.003$; see Fig. 3B). No significant difference was found in the other two groups.

No other significant differences were found.

On ET data a $3 \times 2$ Anova with one between-subject factor, Group (three levels: $\mathrm{N}+, \mathrm{N}-, \mathrm{C}$ ) and one within-subject factor, Task (two levels: preattentive, attentive) was performed. The factor Group was significant $\left[\mathrm{F}(2,21)=10.11 ; \mathrm{p}=.0008\right.$; partial $\left.\eta^{2}=0.49\right]$. Post-hoc analyses showed that $\mathrm{N}+$ were slower $(\mathrm{N}+$ mean $=76.94 \mathrm{~s}, \mathrm{SD}=41.41)$ than the other two groups $(\mathrm{N}-$ mean=37.91 s, SD=12.82; $\mathrm{C}$ mean=20.24 s, $\mathrm{SD}=5.21 ; \mathrm{p}<.006$ for each comparisons). The factor Task [F (2, $21)=7.62 ; p=.012 ;$ partial $\left.\eta^{2}=0.266\right]$ was also significant. Post-hoc analyses indicated that ETs were slower on the attentive (mean=52.12 s, $\mathrm{SD}=45.57$ ) than the on preattentive task (mean=37.94 s; $\mathrm{SD}=25.35$ ). No other significant differences were found.

Correlation analyses on omissions did not show any significant result. However, correlation analyses on ET showed that in $\mathrm{N}+$ patients the difference between left and right omissions on the Diller task was positively correlated with the execution time of both preattentive and attentive cancellation tasks.

\subsection{Experiment 2}

On the omission data a $3 \times 2 \times 2 \times 2$ Anova with one between-subject factor Group (three levels: $\mathrm{N}+, \mathrm{N}-, \mathrm{C}$ ) and three within-subject factors, Task (three levels: number three, even numbers, multiples), Side (two levels: Left and Right), and Background (two levels: preattentive and attentive) was performed. Post-hoc analyses were performed using the Newman-Keuls test.

The factor Group was significant $[\mathrm{F}(2,21)=28.14 ; \mathrm{p}<.0001$; partial $\left.\eta^{2}=0.728\right]$. Post-hoc analyses showed that $\mathrm{N}+$ omitted more targets $(\mathrm{N}+$ mean $=2.59, \mathrm{SD}=2.37)$ than the other two groups $(\mathrm{N}-$ mean $=0.33$, $\mathrm{SD}=0.55 ; \mathrm{C}$ mean $=0.29, \mathrm{SD}=0.6 ; \mathrm{p}<.0001$ for each comparisons). The factors Task $\left[\mathrm{F}(2,42)=22.39 ; \mathrm{p}<.0001\right.$; partial $\left.\eta^{2}=0.516\right]$ and Side $\left[F(1,21)=24.24 ; p<.0001\right.$; partial $\left.\eta^{2}=0.535\right]$ were also significant. Post-hoc analyses indicated that overall more omissions were made on the M3 task (mean=1.67, $\mathrm{SD}=2.08)$ than on the other two tasks (N3 mean=0.66, $\mathrm{SD}=1.54 ; \mathrm{EN}$ mean=0.89, $\mathrm{SD}=1.58 ; \mathrm{p}<.0001$ for each comparisons). In addition, overall more omissions were observed on the left (mean=1.56, $\mathrm{SD}=2.28$ ) than on the right (mean=0.58, $\mathrm{SD}=0.8$ ) side of the page. A significant Group
$X$ Task interaction $\left[F(4,42)=3.74 ; p=.01\right.$; partial $\left.\eta^{2}=0.262\right]$ was accounted for by the fact that $\mathrm{N}+$ patients made more omissions on the multiples task in comparison to the other two groups $(p<.01$ for each comparisons). A significant Group X Task X Side interaction $\left[F(4,42)=3.35 ; p=0.01\right.$; partial $\left.\eta^{2}=0.242\right]$ was accounted for by a higher number of left-sided omissions on the multiples task in the $\mathrm{N}+$ than in the $\mathrm{N}-$ and $\mathrm{C}$ groups $(\mathrm{p}<.0005$ for each comparisons, see Fig. 4A). No significant difference in Task or Side was found in N- and $\mathrm{C}$ groups and they did not differ between them. Interestingly, post-hoc analyses also showed that on the right side of the display $\mathrm{N}+$ patients omitted less even numbers than numbers 3 or multiples of $3(p<.02$ for each comparisons), suggesting that searching for even numbers in right space had an advantage with respect to the other two tasks (Fig. 4(B)). On this task, in the right side of space, $\mathrm{N}+$ patients' performance was not significantly different from $\mathrm{N}-$ patients' and control participants' performance. No differences on task performance were observed between $\mathrm{N}-$ and $\mathrm{C}$ groups within the left or right hemispaces.

On ET data a $3 \times 3 \times 2$ Anova with one between-subject factor, Group (three levels: $\mathrm{N}+, \mathrm{N}-, \mathrm{C}$ ) and two within-subject factors, Task (three levels: number three, even numbers, multiples) and Background (preattentive and attentive) was performed. Post-hoc analyses were performed using the Newman-Keuls test.

The factor Group was significant $[\mathrm{F}(2,21)=14.63 ; \mathrm{p}=.0001$; partial $\left.\eta^{2}=0.583\right]$. Post-hoc analyses showed that $\mathrm{N}+$ were slower $(\mathrm{N}+$ mean $=119.95 \mathrm{~s}, \mathrm{SD}=64.74)$ than the other two groups $(\mathrm{N}-$ mean=90.42 s, SD=68.35; $\mathrm{C}$ mean=39.35 s, SD=19.12; $\mathrm{p}<.001$ for each comparisons). The factor Task $[\mathrm{F}(2,42)=39.76 ; \mathrm{p}<.0001$; partial $\left.\eta^{2}=0.654\right]$ was also significant. Post-hoc analyses indicated overall that participants were slower on the multiples (mean=131 s, $\mathrm{SD}=75.74$ ) than on the other two tasks (N3 mean=56.05 s, $\mathrm{SD}=40.27$; $\mathrm{EN}$ mean=62.09 $\mathrm{s}, \mathrm{SD}=41.81 ; \mathrm{p}<.001$ for each comparisons). The interactions Group X Task $[\mathrm{F}(2,21)=3.42 ; \mathrm{p}=.01$; partial $\left.\eta^{2}=0.245\right]$, Group X Background $[F(2,42)=5.73 ; p=.01$; partial $\left.\eta^{2}=0.353\right]$, and Task X Background $[F(4,42)=3.24 ; p=.04$; partial $\left.\eta^{2}=0.133\right]$ were also significant. Post-hoc analyses of the Group $X$ Task interaction showed that both $\mathrm{N}+$ and $\mathrm{N}-$ patients were significantly slower on the multiples than on the other two tasks $(p<.01$ for each comparisons) and the two groups did not differ between them. The $\mathrm{C}$ group performance did not differ across tasks (see Fig. 5).

Finally, the three-way interaction Group X Task X Background [F $(4,42)=5.74 ; p=.0008$; partial $\left.\eta^{2}=0.353\right]$ was also significant (Fig. 6). 


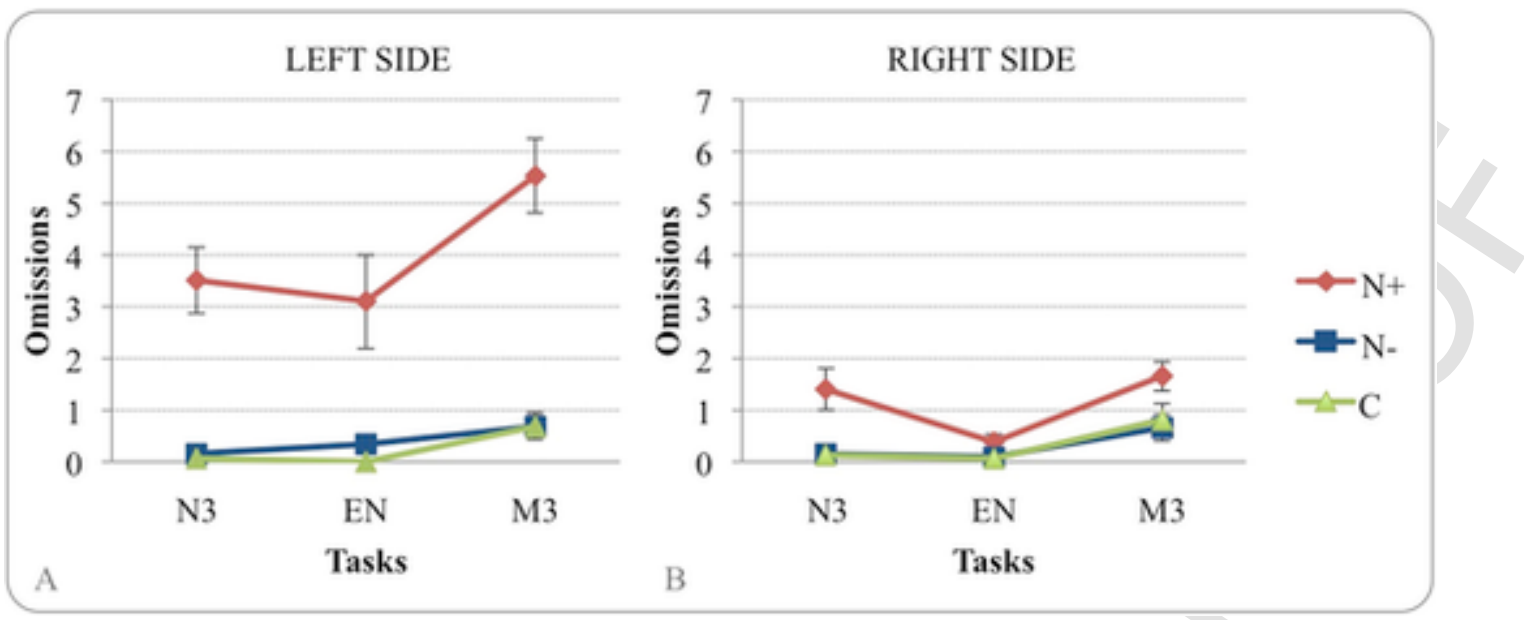

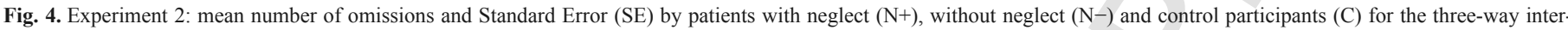

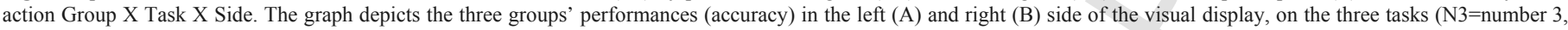

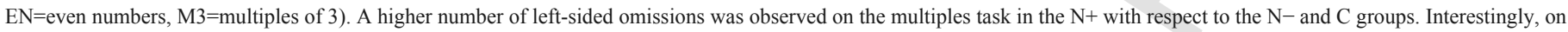
the right side of the display, $\mathrm{N}+$ patients omitted less even numbers than numbers 3 or multiples of 3 .

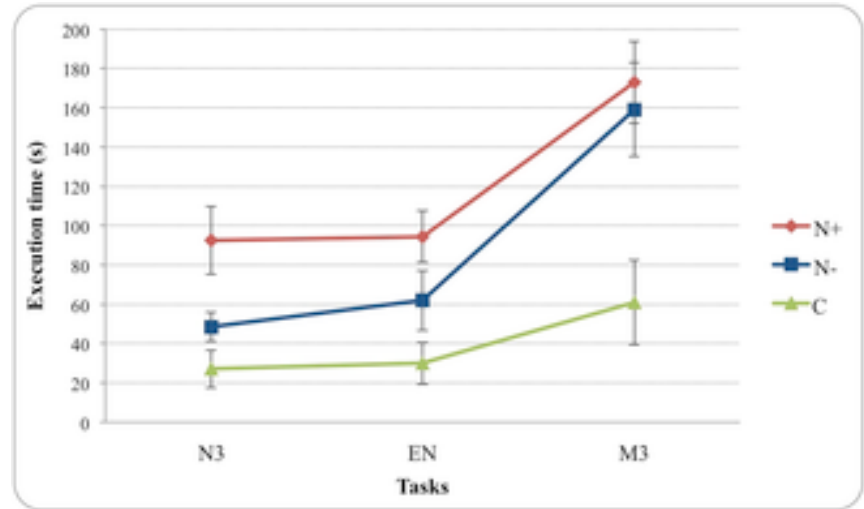

Fig. 5. Experiment 2: mean Execution Time and Standard Error (SE) by patients with neglect $(\mathrm{N}+)$, without neglect $(\mathrm{N}-)$ and control participants $(\mathrm{C})$ for the two-way interaction Group X Task. The graph shows the performance of the three groups in the three tasks $(\mathrm{N} 3=$ search for number $3, \mathrm{EN}=$ search for even numbers, $\mathrm{M} 3=$ search for multiples of 3). $\mathrm{N}+$ and $\mathrm{N}-$ patients were significantly slower in the multiples than in the other two tasks and the two groups did not differ between them.

Post-hoc analyses showed that the three-way interaction was accounted for by a significant increase of $\mathrm{N}+$ patients' ET when searching for multiples on the attentive with respect to the preattentive background $(\mathrm{p}=0.001)$.

Correlation analyses on omissions showed that, in $\mathrm{N}+$ patients, the rightward bisection error was positively correlated with the difference between left and right omissions on the 'searching for number 3' task when the background was preattentive. In addition, the difference between left and right omissions on the Diller task was positively correlated with the difference between left and right omissions on the searching for multiples task when the background was attentive. Thus, correlation analyses suggested that the exploration bias captured by a task requiring to serially focus attention on numbers visual features (searching for numbers containing the digit 3) was related to the rightwards orientation bias as revealed by the bisection task. On the other hand, the degree of exploration bias shown on the most demanding task (searching for multiples on the attentive background) was related to the neglect bias as revealed by the Diller task. Correlation analyses on ET showed that in $\mathrm{N}+$ patients the difference between left and right omissions on the Diller task was positively corre- lated with the execution time on the searching for even numbers task when the background was attentive.

\section{Discussion}

Modulation of neglect on cancellation tasks by perceptual and cognitive factors may contribute to unveil the neurocognitive mechanisms influencing visuospatial attention. Although there is evidence that variables not confined to stimulus visuospatial features (Robertson et al., 1998; Neppi-Mòdona, 1999; Chatterjee et al., 2000; Ricci and Chatterjee, 2004; Ricci et al., 2005; Husain and Rorden, 2003) may affect neglect severity, a clear cut picture on how cognitive factors influence spatial attention is still missing.

Here we tested whether neglect is exclusively dependent on a deficit of the selective spatial attention system or might be also modulated by other non-spatial cognitive variables. To this aim, we manipulated bottom-up and top-down task determinants in order to investigate the influence of these factors on visual search performance in patients with and without neglect and in control participants. In experiment 1, participants performed 'preattentive' and 'attentive' search of simple visual targets (shapes); in experiment 2 the top-down demands of the task were manipulated while keeping constant targets and distractors perceptual features. In this latter experiment, two tasks requiring different levels of cognitive complexity, or a task simply requiring the recognition of a specific number, were employed. The three tasks were performed employing the same preattentive and attentive backgrounds used in experiment 1 .

The results of experiment 1 showed that higher attentional requests (i.e. the attentive background) worsened performance exclusively in patients with neglect, in line with previous findings (Aglioti et al., 1997) and with theories that interpret neglect as a deficit of the attentional system (Heilman et al., 1987; Kinsbourne, 1987). However, in experiment 1 , the lack of a significant three-way interaction suggested a lack of sensitivity of the attentive texture condition in selectively worsening left-sided neglect. This interpretation is supported by the positive correlation between neglect on the Diller task and the execution time of both preattentive and attentive tasks. On the other hand, results of experiment 2 showed that searching for multiples exacerbated left-sided neglect, especially on the 'attentive' background, suggesting the occurrence of interactions between spatial and 


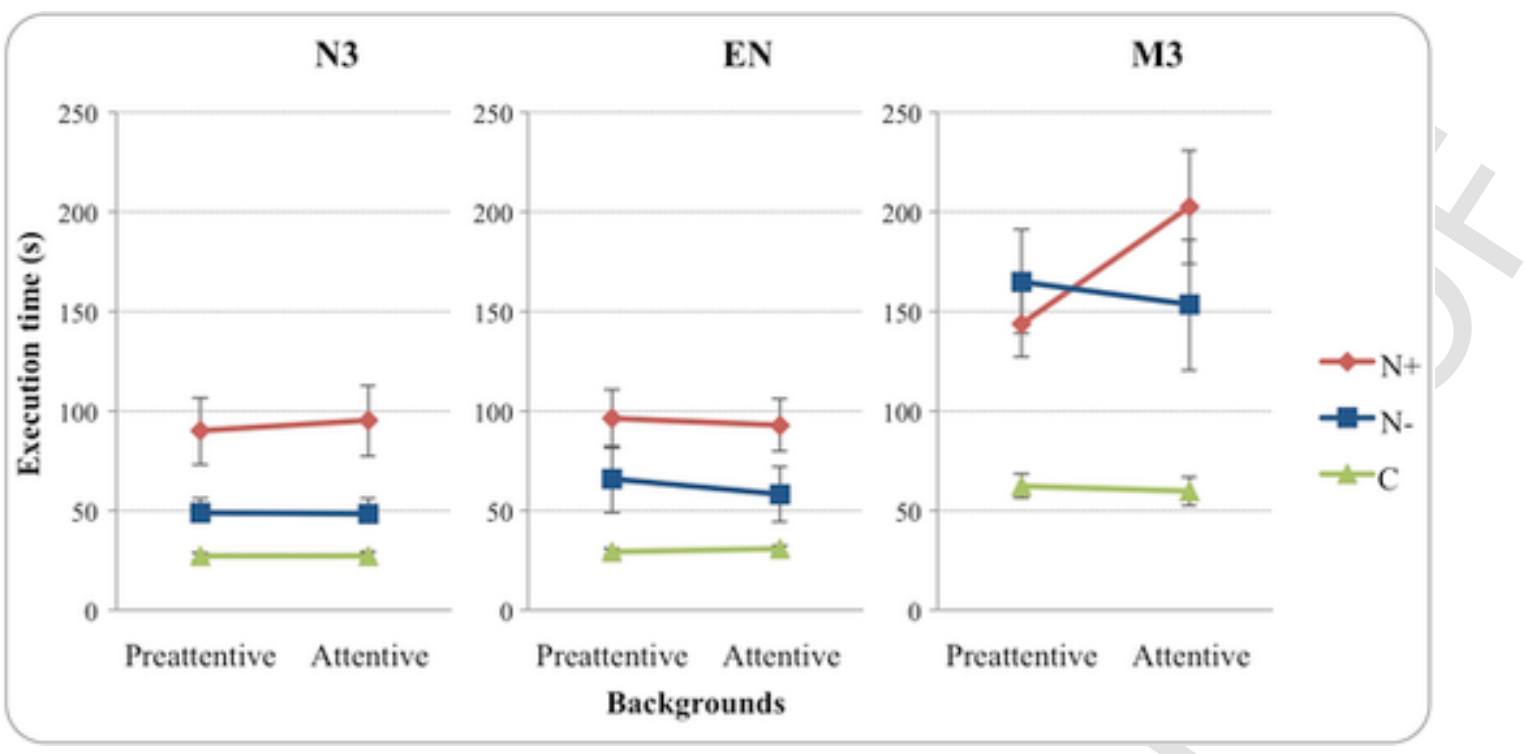

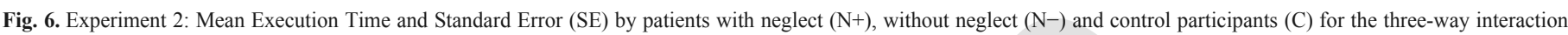

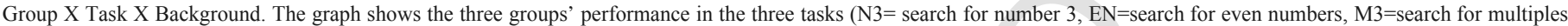

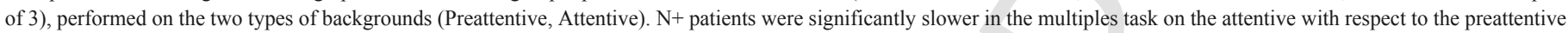
background. In this task, $\mathrm{N}+$ and $\mathrm{N}-$ patients had equivalent performances on the preattentive background.

non-spatial processes. In addition, this task slowed down performance of patients without neglect (i.e., produced an increment in the task execution time). It is worth noting that in the absence of a sensitive measure, such as the ET, the similarity in performance between patients with and without neglect on the multiples task would have been missed. Hence, the use of a complex cognitive process involving target identification seems to represent a more demanding task for righthemisphere lesioned patients, independently of the presence or absence of neglect. This result is consistent with the evidence that extensive right-hemisphere lesions, involving a network of frontal and parietal cortices (Pardo et al., 1991; Rueckert and Grafman, 1996), impair the ability to maintain sustained attention (Heilman and Abell, 1979; Coslett et al., 1987; Wilkins et al., 1987; Rueckert and Grafman, 1996). Although previous studies have suggested that a non-spatial deficit of sustained attention can affect spatial neglect (Robertson et al., 1995, 1997), the two impairments have been usually thought to be independent disorders (Wilkins et al., 1987; Robertson et al., 1998). The use of a mathematical task to identify targets might impose a significant cost to non-spatial attentional resources that are limited in patients with right-hemisphere lesions, and further aggravate the orientation bias implicated in spatial neglect (Robertson et al., 1995, 1997, 1998). Indeed, even in the healthy brain, charging a visual task with a high cognitive load has deleterious effects on the ability to focus attention (Lavie, 2010).

An interpretation of the aggravation of the spatial deficit when searching for multiples as a consequence of hyper-activation of the intact left hemisphere (Kinsbourne, 1977) triggered by mathematical processing (Mennemeier et al., 2004) does not seem to be supported by our findings. Indeed, searching for even numbers - a task that is supposed to engage the left hemisphere, given its numerical and semantic nature (Sergent, 1990; Dehaene and Cohen, 1991) - did enhance neglect patients' performance within the right space (as predicted by Kinsbourne's inter-hemispheric rivalry account), but did not worsen left neglect. It is worth noting that searching for even numbers does not require to focus attention as much as searching for the number 3, and this might also explain enhanced performance on the former task. A more plausible interpretation of our results is that us- ing a mathematical, relatively complex task to identify targets (multiples of 3 ) is cognitively more demanding than employing a simple semantic categorization (i.e. accessing semantic number knowledge, Dehaene et al., 1993) to discriminate targets (even numbers) from distractors.

The finding that a higher cognitive load worsens deficits of contralesional spatial attention is in line with previous evidence (Robertson and Frasca, 1992; Bonato et al., 2010, 2012) and has important clinical consequences. As shown by Bonato et al. (2010,2012,2013) computer-based, resource-demanding, dual-task procedures may reveal contralesional spatial disorders in patients not manifesting symptoms on standard clinical assessment. Hence, these conditions may represent important manipulations for assessing the presence of disorders that, if not detected, might subsequently emerge and interfere with daily living normal activities. However, Bonato et al.'s $(2010,2013)$ computer-based dual-tasks require patients to report the presence of lateralized stimuli, therefore resulting not suitable to measure changes of performance in patients with neglect at standard testing, especially if they are also affected by hemianopia (because of floor effects). In addition, in a single case study, Bonato et al. (2012) reported that several cancellation tasks performed under additional working memory load were almost ineffective in producing contralesional omissions in a chronic patient who still manifested a high rate of omissions at computer-based detection testing (Bonato, 2015). In contrast to Bonato et al.'s protocols (Bonato et al., 2010, 2012, 2013), the searching for multiples task, proposed here, was effective in worsening spatial neglect in patients showing symptoms at standard testing, while it did not affect the rate of contralesional omissions in patients without neglect (as in Robertson and Frasca study, 1992), although increasing their execution time. Thus, differently from Protocols of Bonato et al. $(2012,2013,2015)$, our task might be applied in chronic patients with severe neglect, even when affected by hemianopia. Indeed, despite the presence of visual field defects, patients with neglect showed top-down modulation of contralesional cancellation bias. Another advantage of the present task is that it is suitable to be employed in clinical settings where a computer might not be available. 
The current findings confirm the -seldom addressed- evidence of task dependency of neglect severity, and provide new manipulations, based on top down control, modulating left-sided neglect. They also suggest that interventions apt to restore right hemisphere cerebral activation (i.e. sustained attention) might be particularly effective in improving spatial disorders (Robertson et al., 1998).

The result that the background configuration affected neglect patients' performance in the more demanding cognitive task (i.e. searching for multiples) is interesting in its own right, since it suggests the existence of bidirectional influences between higher level cognitive factors and lower level perceptual ones, in keeping with the evidence of spared preattentive processing in patients with neglect (Ricci et al., 2000, 2004; Pia et al., 2004; Vallar and Daini, 2006).

One limitation of the current study is the absence of brain scans that prevent a precise mapping of patients' brain lesions. The small sample size of the three groups constitutes another limitation. Nonetheless, previous works on these issues employed sample sizes similar to ours (Robertson and Frasca, 1992; Bonato et al., 2013), making therefore possible a direct comparison of results across studies. In addition, our statistical analyses showed medium to large effect size values, suggesting that, from a clinical point of view, the tasks proposed here can be considered a reliable paradigm for assessing performance in patients with neglect. Visual field defects were evaluated using a simple confrontation method (Bisiach et al., 1997), as in previous studies (Bisiach et al., 1997; Aglioti et al., 1997). Unfortunately, more sophisticated methods, such as, for example, the Goldmann perimetry, were not available in the clinic where patients were recovered and examined, preventing a finer and more precise assessment of visual field defects. Finally, because of patients' time constraints and clinical conditions, we had to use a limited number of clinical tests. The use of additional attentional (for example some of the TAP subtests, Zimmermann and Fimm, 2002) and neuropsychological tests, besides line bisection and cancellation, would have allowed to correlate our findings to other measures of attention in order to draw clearer and stronger conclusions. Future studies employing more extensive clinical examination in larger groups of patients are needed to further explore and validate our findings.

In conclusion, this study suggests that exacerbation of the orientation bias in patients with neglect during execution of a demanding, non-spatial, cognitive task might be explained by a deficit of sustained attention due to the right-hemisphere lesion. In order to further investigate this hypothesis in brain-damaged patients, future studies should also consider the possible contribution of left-hemisphere lesions in the modulation of spatial attention under conditions which impose a heavy load on high-level cognitive functions.

\section{Conflict of interests}

The authors report no actual or potential conflicts of interests.

\section{Acknowledgements}

The study has been supported by local funds (ex 60\%) from the University of Turin, the Carlo Molo Foundation Onlus and the San Paolo Foundation. We would like to thank Erica De Stefano for her valuable help with data collection and Maria Luisa Piatti for her contribution to data analyses. We wish to thank the reviewers, Dr. Mario Bonato and Dr. Arnaud Saj, for their valuable comments and suggestions.

\section{References}

Aglioti, S., Smania, N., Barbieri, C., Corbetta, M., 1997. Influence of stimulus salience and attentional demands on visual search. Brain Cogn. 34 (3), 388-403.

Albert, M.L., 1973. A simple test of visual neglect. Neurology 23, 658-664.

Bergen, J.R., Julesz, B., 1983. Parallel versus serial processing in rapid discrimination. Nature 303, 696-698.

Berti, A., Frassinetti, F., 2000. When far becomes near: remapping of space by tool use. J. Cogn. Neurosci. 12, 415-420.

Bisiach, E., Vallar, G., Perani, D., Papagno, C., Berti, A., 1986. Unawareness of disease following lesions of the right hemisphere: anosognosia for hemiplegia and anosognosia for hemianopia. Neuropsychologia 24, 471-482.

Bisiach, E., Pattini, P., Rusconi, M.L., Ricci, R., Bernardini, B., 1997. Unilateral neglect and space constancy during passive locomotion. Cortex 33, 313-322.

Bisiach, E., Ricci, R., Lai, E., De Tanti, A., Inzaghi, M.G., 1999. Unilateral neglect and disambiguation of the Necker cube. Brain 122, 131-140.

Bonato M. 2015. Unveiling residual, spontaneous recovery from subtle hemispatial neglect three years after stroke Front Hum. Neurosci. 9413

Bonato M. Priftis K. Umiltà C. Zorzi M. 2013. Computer-based attention-demanding testing unveils severe neglect in apparently intact patients Behav. Neurol. $251-3$

Bonato, M., Priftis, K., Marenzi, R., Umiltà, C., Zorzi, M., 2010. Increased attentional demands impair contralesional space awareness following stroke. Neuropsychologia 48 (13), 3934-3940.

Bonato, M., Priftis, K., Marenzi, R., Umiltà, C., Zorzi, M., 2012. Deficits of contralesional awareness: a case study on what paper-and-pencil tests neglect. Neuropsychology 26 (1), 20-36.

Chatterjee, A., Mennemeier, M., Heilman, K.M., 1992. Search patterns and neglect: a case study. Neuropsychologia 30 (7), 657-672.

Chatterjee, A., Thompson, K.A., Ricci, R., 1999. Quantitative analysis of cancellation tasks in neglect. Cortex 35 (2), 253-262.

Chatterjee, A., Ricci, R., Calhoun, J., 2000. Weighing the evidence for cross over in neglect. Neuropsychologia 38 (10), 1390-1397.

Coslett, H.B., Bowers, D., Heilman, K.M., 1987. Reduction in cerebral activation after right hemisphere stroke. Neurology 37 (6), 957-962.

Dehaene, S., Cohen, L., 1991. Two mental calculation systems: a case study of severe acalculia with preserved approximation. Neuropsychologia 29 (11), 1045-1054.

Dehaene, S., Bossini, S., Giraux, P., 1993. The mental representation of parity and number magnitude. J. Exp. Psychol. 122 (3), 371-396.

Diller, L., Weinberg, J., 1977. Hemi-inattention in rehabilitation. The evolution of a rational remediation program. In: Weinstein, E.A., Friedland, R.P. (Eds.), Hemi-inattention and Hemisphere Specialization. Raven Press, New York, pp. 62-82.

Diller L. Ben-Yishay Y. Gerstmann L. Goodkin R. Gordon W. Weinberg J. 1974 Studies in Cognition and Rehabilitation in Hemiplegia New York University Medical Center New York

Donnelly, N., Guest, R., Fairhurst, M., Potter, J., Deighton, A., Patel, M., 1999. Developing algorithms to enhance the sensitivity of cancellation tests of visuospatial neglect. Behav. Res. Methods Instrum. Comput. 31 (4), 668-673.

Eglin, M., Robertson, L.C., Knight, R.T., 1989. Visual search performance in the neglect syndrome. J. Cognit. Neurosci. 1, 372-385.

Folstein, M.F., Folstein, S.E., McHugh, P.R., 1975. Mini-Mental State: a practical method for grading the state of patients for the clinician. J. Psychiatr. Res. 12, 189-198.

Heilman, K.M., Abell, T.V.D., 1979. Right hemisphere dominance for mediating cerebral activation. Neuropsychologia 17, 315-321.

Heilman, K.M., Schwartz H.D. Watson, R.T., 1978. Hypoarousal in patients with the neglect syndrome and emotional indifference. Neurology 28 229-232.

Heilman, K.M., Watson, R.T., Valenstein, E., 1993. Neglect and related disorders. In: Heilman, K.M., Valenstein, E. (Eds.), Clinical Neuropsychology, 3rd ed. Oxford University Press, New York, pp. 279-336.

Heilman K.M. Watson R.T. Valenstein E. Goldberg M.E. 1987. Attention: behavior and neural mechanisms In: Mountcastle V.B. Plum F. Geiger S.R. (Eds.), Handbook of Physiology V American Physiological Society Bethesda pp 461-481

Husain, M., Kennard, C., 1997. Distractor-dependent frontal neglect. Neuropsychologia $35,829-841$.

Husain, M., Rorden, C., 2003. Non-spatially lateralized mechanisms in hemispatial neglect. Nat. Rev. Neurosci. 4, 26-36.

Ishiai, S., Sugishita, M., Odajima, N., Yaginuma, M., Gono, S., Kamaya, T., 1990. Improvement of unilateral spatial neglect with numbering. Neurology 40 (9), 1395-1398.

Julesz, B., 1981. Textons, the elements of texture perception and their interaction. Nature 290, 91-97.

Julesz, B., 1987. Preattentive human vision: Link between neurophysiology and psychophysics. In: Mountcastle, V.B., Plum, F., Geiger, S.R. (Eds.), Handbook of Physiology, V. American Physiological Society, Bethesda, pp. 585-604.

Kaplan, R.F., Verfaellie, M., Meadows, M.E., Caplan, L.R., Pessin, M.S., DeWitt, L.D., 1991. Changing attentional demands in hemispatial neglect. Arch. Neurol. 48, 1263-1266. 
Kartsounis, L.D., Findley, L.J., 1994. Task specific visuospatial neglect related to density and salience of stimuli. Cortex 30 (4), 647-659.

Kinsbourne, M., 1977. Hemi-neglect and hemisphere rivalry. Adv. Neurol. 18, 41-49.

Kinsbourne, M., 1987. Mechanisms of unilateral neglect. In: Jeannerod, M. (Ed.), Neurophysiological and Neuropsychological Aspects of Spatial Neglect. North Holland Amsterdampp. 69-86.

Lavie, N., 2010. Attention, distraction, and cognitive control under load. Curr. Dir. Psychol. Sci. 19, 143-148http://dx.doi.org/10.1177/0963721410370295.

Mark, V.S., Kooistra, C.A., Heilman, K.M., 1988. Hemispatial neglect affected by non neglected stimuli. Neurology 38, 1207-1211.

Mark V.W. Heilman K.M. 1997. Diagonal neglect on cancellation Neuropsychologia 35 (11), 1425-1436

Marshall, J.C., Halligan, P.W., 1996. Hemispheric antagonism in visuo-spatial neglect: a case study. J. Int. Neuropsychol. Soc. 2 (5), 412-418.

Mennemeier, M., Rapcsak, S.Z., Dillon, M., Vezey, E., 1998. A search for the optimal stimulus. Brain Cogn. 37 (3), 439-459.

Mennemeier, M.S., Morris, M., Heilman, K.M., 2004. Just thinking about targets can aggravate neglect on cancellation tests. Neurocase 10 (1), 29-38.

Mesulam, M.M., 1985. Principles of Behavioral Neurology. F.A. Davis., Philadelphia

Neppi-Mòdona, M., 1999. Influence of response modality on awareness of contralesional tactile stimuli in right brain damaged patients. Cortex 35 (5), 687-699.

Neppi-Mòdona M. Savazzi S. Ricci R. Genero R. Berruti G. Pepi R. 2002. Unilateral neglect and perceptual parsing: a large-group study Neuropsychologia 40 (12), $1918-1929$

Neppi-Mòdona, M., Rabuffetti, M., Folegatti, A., Ricci, R., Spinazzola, L., Schiavone, F., Ferrarin, M., Berti, A., 2007. Bisecting lines with different tools in right brain damaged patients: the role of action programming and sensory feedback in modulating spatial remapping. Cortex 43 (3), 397-410.

Pardo, J.V., Fox, P.T., Raichle, M.E., 1991. Localization of a human system for sustained attention by positron emission tomography. Nature 349, 61-64.

Pia L. Ricci R. Gindri P. Vallar G. 2013. Drawing perseveration in neglect: effects of target density J. Neuropsychol. 7 (1), 45-57 http://dx.doi.org/10.1111/j.1748-6653. 2012.02034.x

Pia L. Neppi-Mòdona M. Procopio L. Ricci R. Gindri P. Berti A. 2004. Modulation of space-based and object-based neglect by perceptual parsing Cortex 40 (1), $189-190$

Posner, M.I., 1993. Interaction of arousal and Selection in the posterior Attention Network. in Attention: Selection. In: Baddeley, A., Weiskrantz, L. (Eds.), Awareness and Control, 1993. Clarendon Press, Oxford, pp. 390-405.

Ricci, R., Chatterjee, A., 2004. Sensory and response contributions to visual awareness in extinction. Exp. Brain Res. 157 (1), 85-93.

Ricci, R., Calhoun, J., Chatterjee, A., 2000. Orientation bias in unilateral neglect: representational contributions. Cortex 36 (5), 671-677.

Ricci, R., Pia, L., Gindri, P., 2004. Effects of illusory spatial anisometry in unilateral neglect. Exp. Brain Res. 154 (2), 226-237.

Ricci, R., Genero, R., Colombatti, S., Zampieri, D., Chatterjee, A., 2005. Visuomotor links in awareness: evidence from extinction. Neuroreport $16(8), 843-847$.
Riddoch, M.J., Humphreys, G.W., 1987. Perceptual and action systems in unilateral visual neglect. In: Jeannerod, M. (Ed.), Neurophysiological and Neuropsychological Aspects of Spatial Neglect. pp. 151-181.

Robertson, I.H., Frasca, R., 1992. Attentional load and visual neglect. Int. J. Neurosci. $62,45-56$

Robertson I.H. Mattingley J.B. Rorden C. Driver J. 1998. Phasic alerting of neglect patients overcomes their spatial deficit in visual awareness Nature 395 169-172

Robertson, I.H., Tegnér, R., Tham, K., Lo, A., Nimmo-Smith, I., 1995. Sustained attention training for unilateral neglect: theoretical and rehabilitation implications. J. Clin. Exp. Neuropsychol. 17, 416-430.

Robertson, I.H., Manly, T., Beschin, N., Daini, R., Haeske-Dewick, H., Hömberg, V., Jehkonen, M., Pizzamiglio, G., Shiel, A., Weber, E., 1997. Auditory sustained attention is a marker of unilateral spatial neglect. Neuropsychologia 35, 1527-1532.

Rueckert, L., Grafman, J., 1996. Sustained attention deficits in patients with right frontal lesions. Neuropsychologia 34 (10), 953-963.

Rusconi M.L. Ricci R. Morganti F. 2005. Differential Contributions of Viewer-centered and Environment-centered Representations in Unilateral Neglect In: Columbus F. (Ed.), Focus in Neuropsychology Research Nova Science Publishers New York pp 89-101

Sagi, D., Julesz, B., 1985. "Where" and "what" in vision. Science 228, 1217-1219.

Sarri, M., Greenwood, R., Kalra, L., Driver, J., 2009. Task-related modulation of visual neglect in cancellation tasks. Neuropsychologia 47 (1), 91-103. http://dx.doi. org/10.1016/j.neuropsychologia.2008.08.020.

Sarter M. Givens B. Bruno J.P. 2001. The cognitive neuroscience of sustained attention: where top-down meets bottom-up Brain Res. Rev. 35 (2), 146-160

Sergent, J., 1990. Furtive incursions into bicameral minds: integrative and coordinating role of subcortical structures. Brain 113, 537-568.

Tegnér, R., Levander, M., 1991. Through the looking glass. A new technique to demonstrate directional hypokinesia in unilateral neglect. Brain 114 (1943-1951), 1991.

Treisman, A.M., Gelade, G., 1980. A feature-integration theory of attention. Cogn. Psychol. 12 (1), 97-136.

Vallar, G., Daini, R., 2006. Visual perceptual processing in unilateral spatial neglect. The case of visual illusions. In: Vecchi, T., Bottini, G. (Eds.), Imagery and Spatial Cognition: Methods, Models and Cognitive Assessment. pp. 337-362.

Weintraub, S., Mesulam, M.M., 1988. Visual hemispatial inattention: stimulus parameters and exploratory strategies. J. Neurol. Neurosurg. Psychiatry 51 (12), 1481-1488.

Wilkins, A.J., Shallice, T., McCarthy, R., 1987. Frontal lesions and sustained attention. Neuropsychologia 25, 359-365.

Wilson B. Cockburn J. Halligan P. 1987. Development of a behavioral test of visuospatial neglect Arch. Phys. Med. Rehabil. 68 98-102

Zimmermann, P., Fimm, B., 2002. A test battery for attentional performance. In: Diagnosis (Ed.), Applied Neuropsychology of Attention. Theory, Diagnosis and Rehabilitation. Psychology Press, London, pp. 110-151. 